\title{
Effect of Modified Mechanical Treatment Facilities on SRF Yield in Korea
}

\author{
Mi-Hyun Jo ${ }^{1}$, Byung-Jin Lee ${ }^{2}{ }^{2}$ Taeyoung E\&C co., Ltd., Jai-Young Lee ${ }^{3},{ }^{1,3}$ The University of Seoul
}

\begin{abstract}
An SRF plant which can produce 100 ton/month of SRF, one of the largest manufacturing plants in Korea, was investigated in this study. The actual operated SRF yield at $21.7 \%$ that showed a lower yield than expected; originally designed value was $25.0 \%$. The cause of these results was the difference between characteristics of MSW applied to this plant originally and that which was actual incoming. The MSW led to decrease the separation efficiency of the mechanical treatment process. Thus, each element of the facility was modified. After modification, the SRF yield increased to $30.9 \%$, whereas the physico-chemical properties of SRF were satisfied with domestic standard of SRF regardless of modifying MT facilities.
\end{abstract}

Keywords - MT (Mechanical Treatment), MSW (Municipal Solid Waste), SRF (Solid Refuse Fuel).

\section{INTRODUCTION}

Many countries attempt to reduce the amount of greenhouse gas emissions from their industries. Furthermore, implementation of the Kyoto Protocol makes them committed to ensuring safeguarding the environment from climate change. Therefore, the development of renewable energies becomes a priority issue in industries. Methane is a GHG (green house gas) which constitutes $50-55 \%$ by the total volume of landfill gas (LFG) and has 21-23 times larger global warming potential than $\mathrm{CO}_{2}$.[1] Thus, we need to consider a way of managing waste to give benefits for environmental sustainability.

SRF (solid refuse fuel) [2] is fuel made of waste which is used for energy in a paper-manufacturing plant, heating boiler of a local government in Korea. The amount of MSW (municipal solid waste) increased because of rapid population growth and developed life standard. Incineration is one of the ways to dispose waste. The heating values of MSW, however, were much lower than the SRF while it was decomposed. This means that incomplete combustion from insufficient heating can induce to the creation of harmful materials in exhaust gases. In addition, materials having a high calorific value that are not suitable for composting high calorific value material (containing paper, plastics, textile and wood) is referred to as solid recovered fuel(SRF) or refuse derived fuel(RDF). [3]

In Korea, renewable energy was $2.61 \%$ of primary energy which consisted of $70.9 \%$ for fuels recovered from waste. Thus, the goal for the distribution rate of renewable energy will be $11 \%$ by the year 2030. [4] SRF is one way to achieve this goal. The technologies for the solid waste have been developing continuously and the legislation system has also become more specific to maintain quality, shape and each element contents in the SRF.

In Europe, the definition for fuel generated from MSW has undergone many changes. In the technical literature the most common name was Refuse Derived Fuel (RDF), before use of the term SRF(Solid Recovered Fuel). These changes in terminology were driven by new regulation and accompanying standards.[5]

In Korea, the same phenomenon of amended regulations occurred to foster using fuel from waste. Although, the abbreviation is same as SRF, the definition is a little bit different for SRF (Solid Recovered Fuel) in Europe and Korea (SRF; Solid Refuse Fuel). Originally, the solid fuel was called RDF (Refuse Derived Fuel) which was classified up to this time in Korea. Since January 2013, RDF was changed to SRF that just classified with SRF and Bio-SRF. Because the type of original materials becomes more diverse, there is a need to unify the definition and therefore. The law for solid fuel was amended completely. Table I indicates the differences for classification, quality and grade in accordance with the Act on The Promotion of Saving and Recycling of Resources.

In the United Kingdom, there are CEN 15359 SRF quality standards for net calorific value, chlorine, mercury with five classes. Class 1 for the net calorific value is more than $2500 \mathrm{~kJ} / \mathrm{kg}, 0.2 \%$ of chlorine contents are divided into class 1 , $0.02 \mathrm{~g} / \mathrm{J}$ of mercury in class 1 . The contents of chlorine and, mercury are more restricted in Korea.

The mechanical treatment facilities have two functions. The one thing is to meet industrial purposes to produce SRF, but MT is also a pre-treatment before landfilling or combustion in dedicated incinerators. Recently, the former role is significantly increasing in waste management by an increased need for renewable energy sources.

The purpose of this study was to evaluate the performance of the SRF plant, investigate the SRF yield and figure out the causes of the decreasing yield at this facility and introduce modifications for an improved design for the actual incoming MSW for which such the physico-chemical properties such as bulk density, moisture contents, low heating value, etc. were analyzed. After modifying the facility, we compared the difference of characteristics for SRF and the SRF yield before and after the modifications. 
TABLE I

KOREA REgULATIONS For SOLID REFUSE FUEL

\begin{tabular}{|c|c|c|c|c|c|c|c|c|c|c|}
\hline \multirow{2}{*}{\multicolumn{2}{|c|}{ Parameter }} & \multicolumn{5}{|c|}{ Solid Fuel (Until 2012) } & \multicolumn{4}{|c|}{ Solid Refuse Fuel (Since January of 2013) } \\
\hline & & \multicolumn{2}{|c|}{$\begin{array}{c}\text { RDF } \\
\text { (Refuse Derived Fuel) }\end{array}$} & \multirow{2}{*}{$\begin{array}{c}\text { RPF } \\
\text { (Refuse } \\
\text { Plastic Fuel) }\end{array}$} & \multirow{2}{*}{$\begin{array}{c}\text { TDF } \\
\text { (Tire } \\
\text { Derived Fuel) } \\
\text { - }\end{array}$} & \multirow{2}{*}{$\begin{array}{c}\text { WCF } \\
\text { (Wood } \\
\text { Chip Fuel) } \\
-\end{array}$} & \multicolumn{2}{|c|}{ SRF } & \multicolumn{2}{|c|}{$\begin{array}{c}\text { Bio-SRF } \\
\text { (Biomass-SRF) }\end{array}$} \\
\hline \multicolumn{2}{|c|}{ Type } & Pellet & $\begin{array}{l}\text { Non- } \\
\text { pellet }\end{array}$ & & & & Pellet & $\begin{array}{l}\text { Non- } \\
\text { pellet }\end{array}$ & Pellet & $\begin{array}{l}\text { Non- } \\
\text { pellet }\end{array}$ \\
\hline \multicolumn{2}{|c|}{$\begin{array}{l}\text { Diameter (mm) } \\
\text { *width }\end{array}$} & $\leqq 30$ & - & $\leqq 50$ & - & - & $\leqq 50$ & $\leqq 50^{*}$ & $\leqq 50$ & $\leqq 120$ \\
\hline \multicolumn{2}{|c|}{$\begin{array}{l}\text { Length (mm) } \\
* \text { heigth }\end{array}$} & $\leqq 100$ & $\begin{array}{c}\text { Passing } \\
\text { rate } \geqq 95 \% \\
(50 \mathrm{~mm} \mathrm{x} \\
50 \mathrm{~mm})\end{array}$ & $\leqq 100$ & $\leqq 120$ & $\leqq 100$ & $\leqq 100$ & $\leqq 50^{*}$ & $\leqq 100$ & $\leqq 120$ \\
\hline \multicolumn{2}{|c|}{ Moisture (\% wt.) } & $\leqq 10$ & $\leqq 25$ & \multicolumn{3}{|c|}{$\leqq 10$} & $\leqq 10$ & $\leqq 25$ & $\leqq 10$ & $\leqq 25$ \\
\hline \multicolumn{2}{|c|}{$\begin{array}{c}\text { Low Heating } \\
\text { Value (kcal/kg) }\end{array}$} & \multicolumn{2}{|c|}{$\geqq 3,500$} & \multicolumn{2}{|c|}{$\geqq 6,000$} & $\geqq 3,500$ & $\geqq 3,500$ & $\geqq 3,500$ & $\geqq 3,000$ & $\geqq 3,000$ \\
\hline \multicolumn{2}{|c|}{$\begin{array}{c}\text { Ash } \\
\text { (\% wt., dry basis) }\end{array}$} & \multicolumn{3}{|c|}{$\leqq 20$} & $\leqq 4$ & $\leqq 8$ & $\leqq 20$ & & $\leqq 15$ & \\
\hline \multicolumn{2}{|c|}{$\begin{array}{c}\text { Chlorine } \\
\text { (\% wt., dry basis) }\end{array}$} & \multicolumn{3}{|c|}{$\leqq 2$} & & $\leqq 0.3$ & $\leqq 2$ & & $\leqq 0.5$ & \\
\hline \multicolumn{2}{|c|}{$\begin{array}{c}\text { Sulfur } \\
\text { (\% wt., dry basis) }\end{array}$} & \multicolumn{3}{|c|}{$\leqq 0.6$} & $\leqq 2.0$ & $\leqq 1.2$ & $\leqq 0.6$ & & $\leqq 0.6$ & \\
\hline \multirow{5}{*}{$\begin{array}{c}\text { Metals } \\
\text { (mg/kg, } \\
\text { dry basis) }\end{array}$} & $\mathrm{Hg}$ & \multicolumn{4}{|c|}{$\leqq 1.2$} & $\leqq 1.0$ & $\leqq 1.0$ & & $\leqq 0.6$ & \\
\hline & $\mathrm{Cd}$ & \multicolumn{4}{|c|}{$\leqq 9.0$} & $\leqq 2.0$ & $\leqq 5.0$ & & $\leqq 5.0$ & \\
\hline & $\mathrm{Pb}$ & \multicolumn{4}{|c|}{$\leqq 200.0$} & $\leqq 30$ & $\leqq 150$ & & $\leqq 100$ & \\
\hline & As & \multicolumn{4}{|c|}{$\leqq 13.0$} & $\leqq 2.0$ & $\leqq 13.0$ & & $\leqq 5.0$ & \\
\hline & $\mathrm{Cr}$ & \multicolumn{4}{|c|}{-} & $\leqq 30.0$ & - & & $\leqq 70.0$ & \\
\hline \multirow{4}{*}{$\begin{array}{l}\text { Heating } \\
\text { Value } \\
\text { (kcal/kg) }\end{array}$} & 1 & \multicolumn{5}{|c|}{$\geqq 6,500$} & \multicolumn{4}{|c|}{ - } \\
\hline & 2 & 5,5 & 6500 & 6,000 & 6,500 & $5,500 \sim 6,500$ & & & & \\
\hline & 3 & $\begin{array}{c}4,500 \sim 5,50 \\
0\end{array}$ & - & & & $4,500 \sim 5,500$ & & & & \\
\hline & 4 & $\begin{array}{c}3,500 \sim 4,50 \\
0\end{array}$ & - & & & $3,500 \sim 4,500$ & & & & \\
\hline & 1 & & & .5 & & $<0.3$ & & & & \\
\hline Chlorine & 2 & & & $\checkmark<1.0$ & & - & & & & \\
\hline dry basis) & 3 & & & $\sim<1.5$ & & - & & & & \\
\hline & 4 & & & $v<2.0$ & & - & & & & \\
\hline
\end{tabular}

*Ministry of Environment: Act on the Promotion of Saving and Recycling of Resources Enforcement Regulation (Addendum 7)

\section{FACILITIES}

The SRF plant which was investigated in this study, one of the largest manufacturing plants in Korea, located in the $\mathrm{S}$ landfill in Korea. This plant can produce 100 ton/day of SRF while 200 ton/day of municipal waste was treated. As shown in Fig. 1, it consists of input, shredding, separation, grinding, temporary storage, drying and shape foaming step. In the separation process, there is each step for the size, gravity, magnetic and optical separation in detail. An optical separator using a near-infrared ray was installed a separator using nearinfrared to extract organo-chlorines such as PVC, EDC, VC that contain one or more atoms of chlorine to prevent inducing aromatic compound known as carcinogen during combustion. Among the most important by-products of the PVC lifecycle are dioxin (2,3,7,8-tetrachlorodibenzo-p-dioxins) and a large group of structurally and toxicologically related compounds, collectively called dioxins. Dioxins are never manufactured intentionally but are formed accidentally whenever chlorine gas is used or chlorine-based organic chemicals are burned or processed under reactive conditions.[6] After the separation process, combustible material of waste was dried within $10 \%$ of moisture content, the dried material was placed into temporary storage. Finally, there was a shape forming step for circular with $20 \mathrm{~mm}$ of diameter, $50 \mathrm{~mm}$ of length. 


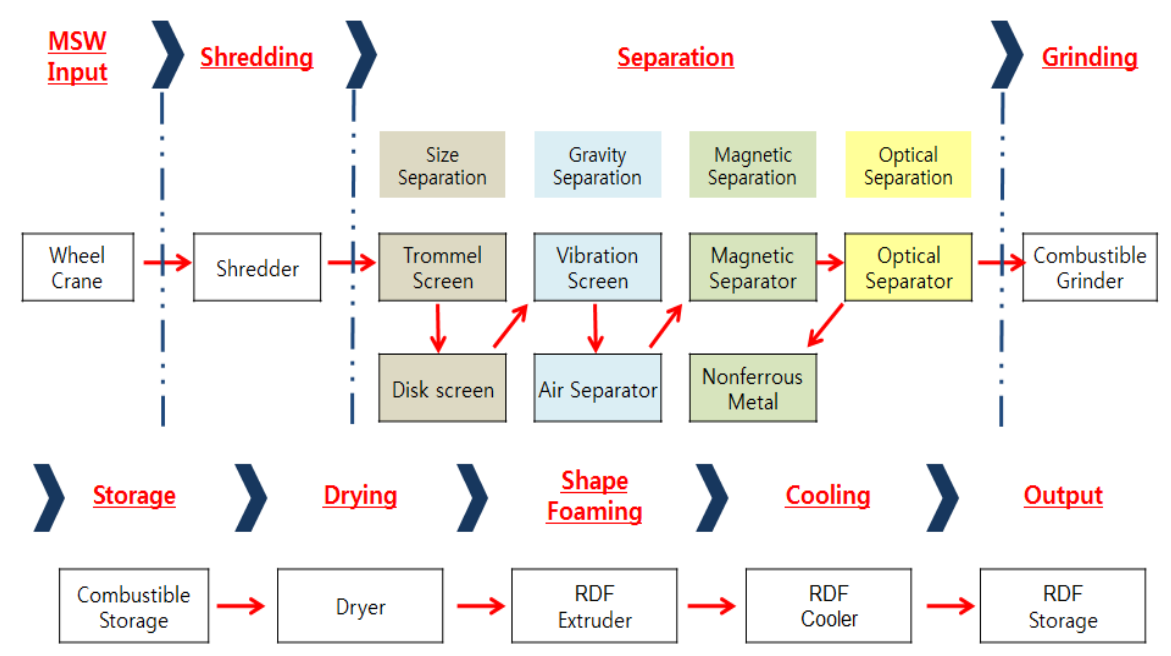

Fig. 1. Flow chart of solid refuse fuel plant for this study

\section{METHODOLOGY}

\section{A. SRF yield}

Generally, SRF production depends on the incoming MSW load.[7,8] It can be described with Eq. (1). We compared designed value and actual operated SRF yield in this plant.

$$
\text { Yield }=\frac{\text { SRF production amount }}{\text { incoming MSW amount (\%) }}
$$

\section{B. . Separating efficiency for the each process of mechanical treatment facilities}

For collecting combustible material, the first step was to separate the waste according to size which composited three kinds of screens. Fig. 2 indicates the process of size separation. After trommel screening, below $100 \mathrm{~mm}$ of waste are transferred to a disk screen, but, more than $100 \mathrm{~mm}$ of those moved to a vibration screen. Finally, the MSW was divided into three kinds of waste (organic, metal and nonmetal material) with below $40 \mathrm{~mm}$ after that process. We collected samples for investigating the separating efficiency in each container with organic, metal and non-metal.

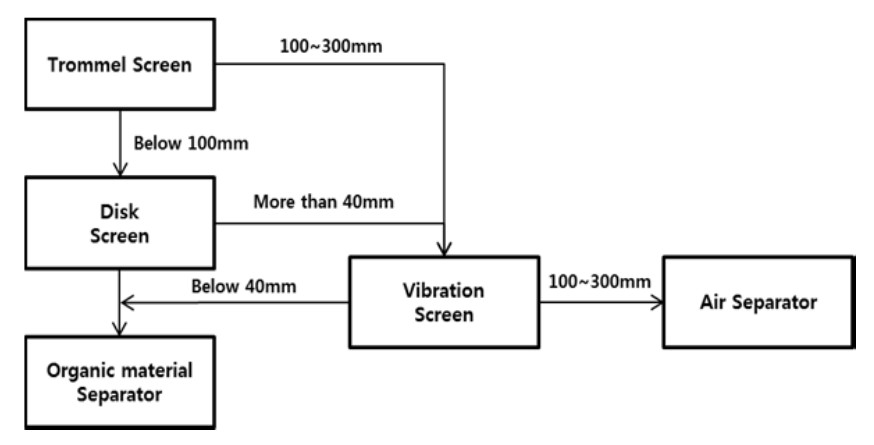

Fig. 2. Scheme for the size separation

\section{Impact factor of SRF yield}

The SRF yield depends on amount of combustible waste which was sorted from municipal solid waste. In order to collect much of the combustible waste, each process must be well matched with actual incoming waste. The efficiency of each process depended on characteristics such as moisture contents, bulk density, and low heating value of waste in that region. Thus we examined the amount of combustible material which could not contribute to SRF by putting into the container with non-combustible material and organic material. We analysed the characteristic of actual incoming municipal waste for: physical composition, bulk density, proximate analysis (moisture, combustible, ash), ultimate analysis (C, H, $\mathrm{O}, \mathrm{N}, \mathrm{S}$ ) using elemental analyzer (Elementar Anazysensysteme, US/Vario EL III, USA), chlorine (Cl) was analyzed by ion chromatography (ICS-1000, Dionex, USA) and heating value (Parr 1261, Parr instrument company, USA) according to waste control act in Korea

\section{Variation of SRF yield after modification of each process for} mechanical treatment facilities

The causes of decreasing SRF yield were analyzed in this by comparing differences between the characteristics of MSW applied to this plant originally and actual incoming. After that, the MT facility was modified and the SRF yield was examined and the followin were analyzed: heating value, chlorine, sulfur, 12 heavy metals, moisture, ash, combustible content for SRF. The experiment period was approximately 12 months in this study.

\section{IV.RESULTS AND DISCUSSION}

\section{A. Comparing intended SRF yield and actual yield}

Originally, the designed value of SRF yield was $25.0 \%$ in this SRF plant. However, actual operated SRF yield was indicated as $21.7 \%$ which means 561.7 ton/month of SRF over 2,592.0 ton/month of input MSW. The SRF yield was about $4 \%$ lower than the intended value.

\section{B. Cause of decreasing SRF yield}

As shown in Fig. 3, the original values were ; $19.0 \%$ of moisture content, $129.0 \mathrm{~kg} / \mathrm{m}^{3}$ of bulk density, $4,190 \mathrm{kcal} / \mathrm{kg}$ of low heating value. The actual values were; $44.4 \%$ of moisture contents, $232.3 \mathrm{~kg} / \mathrm{m}^{3}$, 2,535 kcal $/ \mathrm{kg}$ respectively. In case of bulk density and moisture content, it showed about 
2 times more than expected value. First of all, the amount of moisture content in waste was a very critical thing to determine performance for mechanical treatment. High soaked waste with vinyl not viable for the shedder. Not-cut municipal solid waste which was not the proper size to separate was transported as is to next size separating process.

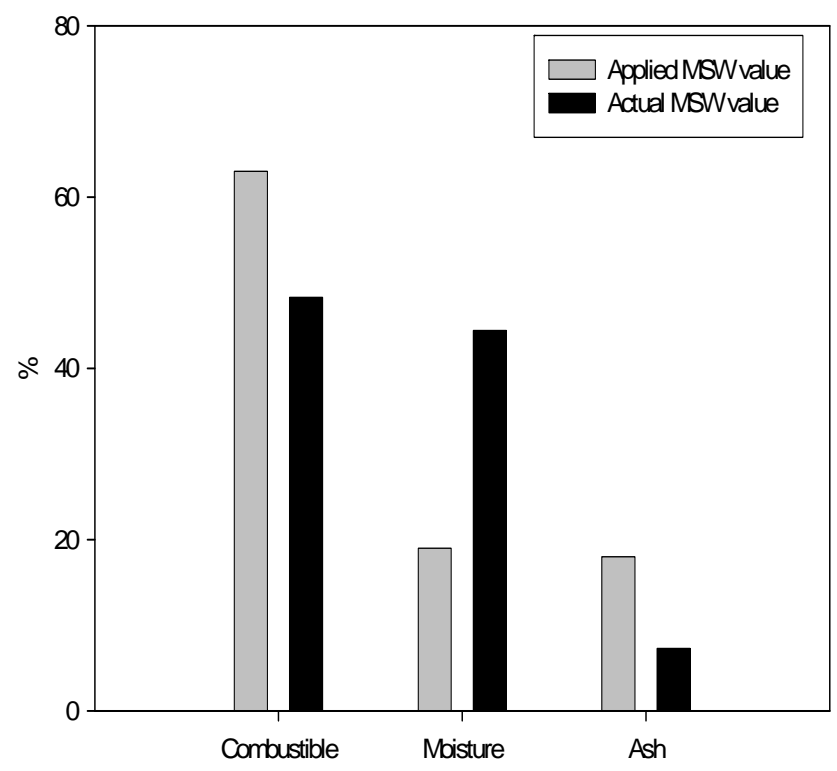

Fig. 3. The different characteristics between applied and actual values

\section{Loss of combustible material in the separating process}

Table II shows the amount of combustible material in the incombustible container and organic material container. $64.5 \%$ (23.7.2 ton/month) of combustible materials were shown while 367.5 ton/month of non-combustible in the container only for the incombustible waste from 40 to $300 \mathrm{~mm}$. $32.6 \%$ (194.9 ton/month) of combustible material for the organic waste. The combustible waste carried out in the incombustible container and organic container. That is why the SRF yield was decreased.

\section{Dryer efficiency according to percentage of water content}

The combustible waste selected by the mechanical treatment dried within $10 \%$ of moisture content. Actually, moisture content was 2.3 times higher than the originally considered value and it had an effect on the dryer performance. Therefore, an experiment was carried out in order to compare different moisture content changes of waste during mechanical treatment. The $30.9 \%$ of moisture containing waste was dried to $10.0 \%, 49.0 \%$ of moisture waste was dried to $12.4 \%$. So, the performance of the dryer was found to be good to treat moist waste. However, the level of moisture of his waste affected the capacity of input waste amount which was significantly decreased from 8,099 kg/hr to 5,855 kg/hr.

\section{E. SRF yield according to mechanical treatment modification}

SRF yield was increased after the modification of mechanical treatment facilities.
TABLE II

COMBUSTIBLE WASTE IN EACH CONTAINER (UNIT: TON/MONTH)

\begin{tabular}{|c|c|c|c|}
\hline \multicolumn{2}{|c|}{$\begin{array}{l}\text { From } 40 \text { to } 300 \mathrm{~mm} \text { MSW in the } \\
\text { incombustible waste container }\end{array}$} & \multicolumn{2}{|c|}{$\begin{array}{c}\text { Below 40mm MSW in the organic } \\
\text { waste container }\end{array}$} \\
\hline $\begin{array}{l}\text { Incombustible } \\
\text { waste }\end{array}$ & 367.51 & Organic waste & 598.78 \\
\hline Combustible waste & 237.17 & Combustible waste & 194.90 \\
\hline Total Weight & 604.68 & Total weight & 793.68 \\
\hline $\begin{array}{l}\text { Combustible waste } \\
\text { ratio (\%) }\end{array}$ & 64.53 & $\begin{array}{c}\text { Combustible waste } \\
\text { ratio (\%) }\end{array}$ & 32.55 \\
\hline
\end{tabular}

In detail, SRF productivity was increased from 561.7 ton/month to 800 ton/month. SRF yield was also increased from $21.7 \%$ to $30.9 \%$. There were variation of productivity and yield for solid refuse fuel by modified facility.

Table III shows the specification of modification for each step in the mechanical treatment facility in order to collect more combustible material and, match with actual physical and chemical composition. The shredder, trammel screen, disk screen, dryer, conveyor shape type and air separator were modified to an improved design for the actual MSW with high moisture content and bulk density.

Most of the parameter for SRF indicated that changes for each process contributed to increase the quality of solid refuse fuel a little bit or almost had similar figures for properties.

Fig. 4 shows that moisture content variation during production process for solid refuse fuel. The moisture content of input waste was $49.8 \%$ on average and, $7.8 \%$ of the moisture content was extracted from the waste during the separation processes.

9.4\% of water content showed after the drying process. Finally, solid refuse fuel contained 9.2\% moisture. Thus, the water content hardly changed between the drying and shape forming steps.

The total amount of municipal solid waste was decreased for solid refuse fuel. In order to collect the missed combustible material, each element of the facility was modified; width of the blade of the shedder from $110 \mathrm{~mm}$ to $63 \mathrm{~mm}$, reducing hole size to separate possible for below $40 \mathrm{~mm}$ of waste and from 40 to $300 \mathrm{~mm}$ of it. Originally, the trammel screen designed for the below $100 \mathrm{~mm}$, from 100 to $300 \mathrm{~mm}$ of waste. Disk screen also modified to $25 \mathrm{~mm}$ wheelbase from $40 \mathrm{~mm}$. Dryer also changed their heat capacity from 2,000,000 kcal/hr to $2,500,000 \mathrm{kcal} / \mathrm{hr}$ to decrease overload. The conveyor type was also modified to apron type with a barrier for preventing the slippage of municipal solid waste with high bulk density. Furthermore, the air separator was also modified to prevent slippage of the waste to expand width of the conveyor belt and make a lower incline of the conveyor belt at the outflow. 
TABLE III

SPECIFICATION OF MODIFIED MECHANICAL TREATMENT FACILITIES

\begin{tabular}{|c|c|c|c|}
\hline Classification & Before modification & After modification & Effect \\
\hline Shredder & $\begin{array}{l}\text { - } 110 \mathrm{~mm} \text { width of the blade of shredder } \\
\qquad 3 \text { hook/piece }\end{array}$ & $\begin{array}{l}\text { - } 63 \mathrm{~mm} \text { width of the blade of shredder } \\
\qquad 6 \sim 7 \text { hook/piece } \\
\bullet \text { increased speed of rotation }\end{array}$ & $\begin{array}{l}\text { Efficient cutting of } \\
\text { small bags with } \\
\text { MSW }\end{array}$ \\
\hline Trommel Screen & $\begin{array}{l}\text { - size hole to separate below } 100 \mathrm{~mm} \text {, } \\
\qquad 100 \sim 300 \mathrm{~mm}\end{array}$ & $\begin{array}{l}\text { - reduced size hole to separate below } 40 \mathrm{~mm}, 40 \sim 300 \\
\text { mm }\end{array}$ & \multirow{2}{*}{$\begin{array}{l}\text { appropriate sizing } \\
\text { separation }\end{array}$} \\
\hline Disk Screen & - wheelbase $40 \mathrm{~mm}$ & • wheelbase 25 mm & \\
\hline Dryer & • 2,000,000 kcal/hr of heat capacity & • 2,500,000 kcal/hr of heat capacity & $\begin{array}{l}\text { decreased overload } \\
\text { of dryer }\end{array}$ \\
\hline Conveyor & - non barrier type & - apron type & \multirow[b]{2}{*}{ prevent slip MSW } \\
\hline Air separator & $\begin{array}{c}\text { - narrow width of inside conveyor belt } \\
\text { • high degree of conveyor belt with exit of air } \\
\text { separator }\end{array}$ & $\begin{array}{c}\text { • wide width of inside conveyor belt } \\
\text { • low degree of conveyor belt with exit of } \\
\text { air separator }\end{array}$ & \\
\hline
\end{tabular}

After modification, the SRF yield was increased from 21.7\% to $30.9 \%$. Originally, the designed value was $25.0 \%$. As well as SRF yield increase, the quality of SRF was also aligned with Korean regulation for low heating value, moisture content and heavy metal contents. Thus, the physico-chemical properties of actual incoming municipal solid waste were a really important thing to run SRF plant

TABLE IV

POLLUTANTS IN THE EXHAUST GAS (DRY BASIS)

\begin{tabular}{|c|c|c|}
\hline Parameter & Standard & Exhaust Gas \\
\hline Dust & $12 \mathrm{mg} / \mathrm{Sm}^{3}$ & $3.60 \mathrm{mg} / \mathrm{Sm}^{3}$ \\
\hline Sulfur Oxides $\left(\mathrm{SO}_{\mathrm{X}}\right)$ & $12 \mathrm{ppm}$ & $6.45 \mathrm{ppm}$ \\
\hline Nitrogen Oxides $\left(\mathrm{NO}_{\mathrm{X}}\right)$ & $12 \mathrm{ppm}$ & $16.19 \mathrm{ppm}$ \\
\hline Hydrogen Chloride $(\mathrm{HCl})$ & $12 \mathrm{ppm}$ & $0.17 \mathrm{ppm}$ \\
\hline
\end{tabular}

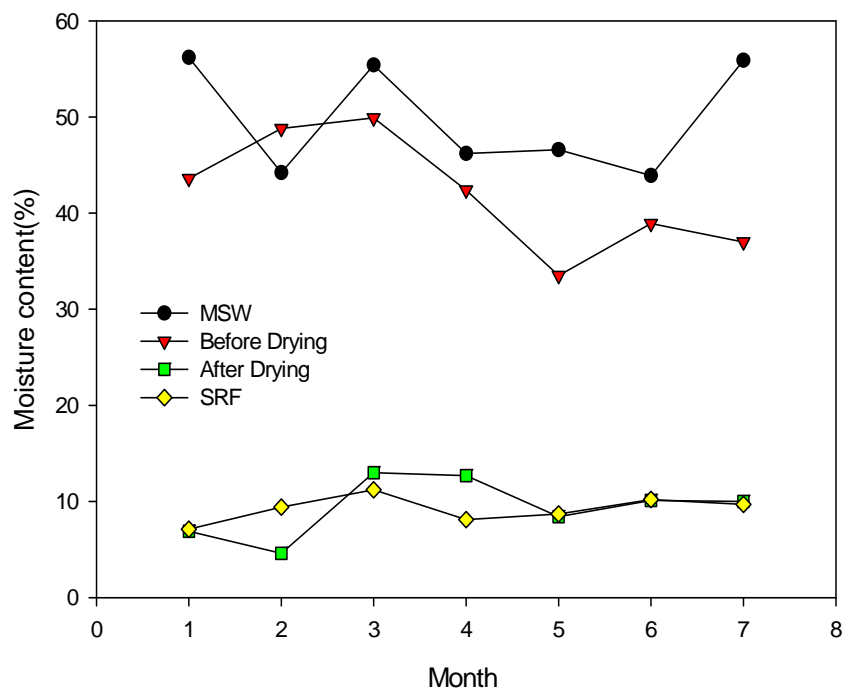

Fig. 4. Moisture content variation between municipal solid waste and solid refuse fuel

\section{F. Physico-chemical properties variation of SRF according to modification}

The data in Table IV provides physical and chemical properties of solid refuse fuel in this plant. The length of SRF was $45.1 \mathrm{~mm}, 6,446 \mathrm{kcal} / \mathrm{kg}$ of high heating value, $4,692 \mathrm{kcal} / \mathrm{kg}$ of low heating value, $0.81 \%$ of chlorine and $5.33 \%$ of moisture before modification of this mechanical treatment. After modification the properties of the SRF were: $42.16 \mathrm{~mm}$ of length, $6,111 \mathrm{kcal} / \mathrm{kg}$ of high heating value, $4,758 \mathrm{kcal} / \mathrm{kg}$ of low heating value, $0.70 \%$ of chlorines. Table IV also provides the contents of hazardous components in solid refuse fuel. Most heavy metal contents were decreased after modification. $13.03 \mathrm{mg} / \mathrm{kg}$ of lead $(\mathrm{Pb}), 0.82 \mathrm{mg} / \mathrm{kg}$ of nickel $(\mathrm{Ni})$ were shown to significantly decrease more than other hazardous components.

Furthermore, the quality of solid refuse fuel met the requirements of the amended regulation as well as the previous standard.

In addition, the experiments for pollutants in the exhaust gas were performed. Dust, NOx, SOx and $\mathrm{HCl}$ contents were analyzed according to the official test method on air pollution. Table $\mathrm{V}$ indicates that the pollution matter contents were shown within the effluent quality standard in Korea 
TABLE V

Physico-Chemical Properties Of Solid Refuse Fuel

\begin{tabular}{|c|c|c|c|}
\hline Parameter & Standard & Before & After \\
\hline Length (mm) & $\leqq 50$ & 45.10 & 42.16 \\
\hline Diameter (mm) & $\leqq 100$ & 18.19 & 18.00 \\
\hline HHV(Dry, kcal/kg) & - & 6,446 & 6,111 \\
\hline HHV (Wet, kcal/kg) & - & 5,527 & 5,215 \\
\hline LHV(Wet,kcal/kg) & $\geqq 3,500$ & 4,692 & 4,758 \\
\hline Chlorine (\%) & $\leqq 2$ & 0.81 & 0.70 \\
\hline Sulfur (\%) & $\leqq 0.6$ & 0.08 & 0.08 \\
\hline Moisture (\%) & $\leqq 10$ & 5.33 & 3.31 \\
\hline Ash (\%) & $\leqq 20$ & 12.93 & 14.50 \\
\hline Combustible (\%) & - & 81.74 & 82.19 \\
\hline $\mathrm{Hg}$ & $\leqq 1.0$ & 1.15 & 0.08 \\
\hline $\mathrm{Cd}$ & $\leqq 5.0$ & ND & ND \\
\hline $\mathrm{Pb}$ & $\leqq 150$ & 39.52 & 13.03 \\
\hline As & $\leqq 13.0$ & ND & ND \\
\hline $\mathrm{Cr}$ & - & 42.39 & 45.09 \\
\hline $\mathrm{Ti}$ & - & ND & ND \\
\hline $\mathrm{Sb}$ & - & 2.44 & 3.45 \\
\hline Co & - & ND & ND \\
\hline $\mathrm{Ni}$ & - & 6.38 & 0.82 \\
\hline $\mathrm{Mn}$ & - & 86.40 & 76.65 \\
\hline V & - & ND & ND \\
\hline $\mathrm{Cu}$ & - & 185.38 & 178.72 \\
\hline
\end{tabular}

Before - Before modification of mechanical treatment facilities; After - After modification of mechanical treatment facilities; Standard - Amended standard in January of 2013; HHV - High Heating Value; LHV - Low Heating Value; ND - Not Detected.

\section{CONCLUSION}

The actual operated SRF yield showed $21.7 \%$ which was lower than the designed value originally; $25.0 \%$. The causes of these results were the different characteristics between the actual incoming municipal solid waste and the originally applied values such as bulk density, moisture content and heating value.

These different properties of municipal solid waste affected each process of SRF production. $44.42 \%$ of high moisture content with incoming waste decreased the efficiency of the separator efficiency. Small black bags with waste in a large size bag could not be cut in the shedder which is also attributed to the low efficiency of the size separation. The lost amount of combustible material was examined in the incombustible material and organic material container. $64.53 \%$ of the combustible material over total weight in the incombustible material container was measured in the incombustible material and $32.55 \%$ of combustible material in the organic material container. After the separation processes, the collected combustible material must be taken to the dryer. However, the combustible material had been misplaced in other containers.

\section{REFERENCES}

1. Shin, H.C., Park, J.W., Kim, H.S., Shin, E.S., Environmental and economic assessment.

2. Ministry of Environment: Act on the Promotion of Saving and Recycling of Resources Enforcement Regulation (Addendum 7)

3. Garg, R. Smith, D. Hill, P.J. Longhurst, S.J.T. Pollard, N.J. Simms, An integrated appraisal of energy recovery options in the United Kingdom using solid recovered fuel derived from municipal solid waste, waste management, 2009, vol. 29, pp. 2289-2297

4. Choi, Y. S., Jeong, D. S., Lee, S. H. A Study on the Energy Effect and Economic Benefit in the Wonju MSW RDF Manufacturing Plant, Journal of Korea Society of Waste Management, 2012, vol. 29, pp. 372378

5. Editorial RDF/SRF: Which perspective for its future in the EU, Waste Management, 2012, vol. 32, pp. 1059-1060. http://dx.doi.org/10.1016/j.wasman.2012.02.017

6. Environmental Impacts of Polyvinyl Chloride (PVC) Building Materials, A briefing paper for the U.S. Green Building Council, Joe Thornton, Ph.D. Columbia Earth Institute, Columbia University

7. Vera, S. R., Thomas, K., Joerg, W., Bernd, B. Material Flow Analysis of RDF-Production Processes, Waste Management, Germany, 2004

8. Scoullos, M., Siskos, P., Zeri, C., Skordilis, A., Ziogas, Ch., Sakellari, A., Giannopoulou, K., Tsiolis, P., Mavroudeas, S., Argyropoulos, I., Roumeliotis, Th. and Skiadi, O. Composition and Chemical Properties of RDF produced at a MSW Mechanical Separation Plant in Greece, Conference on Thermal Processing of MSW, National Technical University of Athens, Greece, 2009

9. Lee, B. J. A Study on the Optimization of RDF Yield with MBT Process and Characteristics. M.S. thesis. Seoul : The University of Seoul, 2012,.pp. 28-65

10. Rada, E. C., Andreottola, G. : RDF/SRF: Which Perspective for its Future in the EU, Waste Management, vol. 32, No. 6, pp. 10591060(2012). http://dx.doi.org/10.1016/j.wasman.2012.02.017

11. Garg, A., Smith, R., Hill, D., Simms, N. and Pollard, S. : Wastes as Co-Fuels: The Policy Framework for Solid Recovered Fuel (SRF) in Europe, with UK Implications, Environmental Science \& Technology, Vol. 41, No. 14, pp. 4868-4874 (2007). http://dx.doi.org/10.1021/es062163e

12. Lupa, C. J., Ricketts, L J., Sweetman, A. and Herbert, B. M. J. : The Use of Commercial and Industrial Waste in Energy Recovery Systems - a UK Preliminary Study, Waste Management, Vol. 31, No. 8, pp. 1759-1764 (2011) . http://dx.doi.org/10.1016/j.wasman.2011.04.002

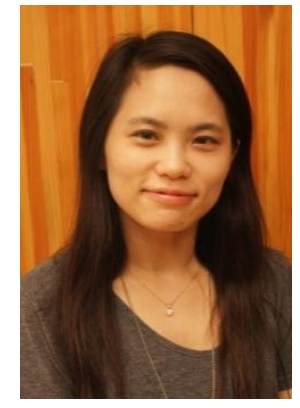

Mi-Hyun Jo is a master's course student of Environmental Engineering at the University of Seoul in Korea. She is a researcher in the Geoenvironmental \& Hazardous Waste Laboratory. Particularly she has done research for the development of neutralizer to ameliorate acid soil using waste materials. Currently, she participates in a project for the inventory design with soil and ground water technologies. Previously she gained a bachelor's degree in chemistry at the Chungnam National University (2009)

Address : The Dept.of Environmental

Engineering, University of Seoul 163 Siripdaero, Dongdaemun-gu, Seoul 130-743, Korea

Phone : +821063172302

E-mail : michellejo0808@gmail.com. 


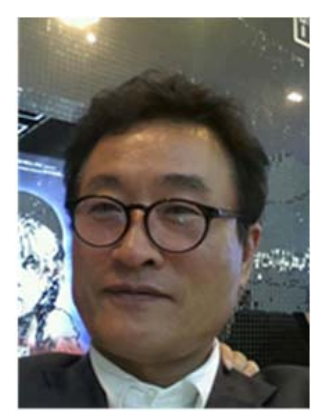

Byung-Jin Lee is the senior managing director of plant division in Taeyoung E\&C. He acquired a Master's Degree for Environmental Engineering at the Seoul University (2012). He is a member of the executive committee in Korea Society of Waste Management. His research interests are MBT(mechanical biological treatment), biogas plant and biomass plant.

Address : 10-2 Yeido-dong Yeongdeungpo-gu Seoul 150-777, Korea

Phone : +82220902031

E-mail : busilee@taeyoung.com

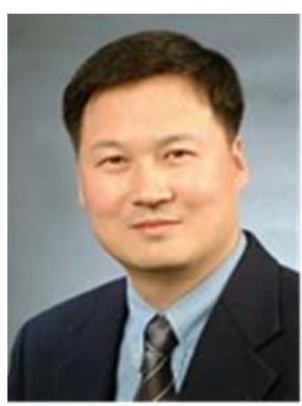

Jai-Young Lee is a professor of the Dept. of Environmental Engineering at University of Seoul in Korea. He is the president of Korean Society of Soil \& Groundwater Environment. He graduated with a Ph.D for Civil Environmental Engineering at Wayne State University in USA(1994). He has worked as head of Seoul Green Environment Center since 2009. He is a member of executive committee in ISEG(International Society of Environment Geotechnics) and worked as the chief editor of Journal of Material Cycles and Waste Management. (SCI-E)

Address : The Dept.of Environmental Engineering, University of Seoul 163 Siripdaero, Dongdaemun-gu, Seoul 130-743, Korea

Phone : +82264902864

E-mail : leejy@uos.ac.kr 